\title{
Teaching Practice Program in the College of Education - its Strengths and Challenges
}

\author{
${\text { Dawit } \text { Yikealo }^{1 *} \text {, Ikali Karvinen }}^{1}$ \\ ${ }^{1}$ Eritrea Institute of Technology, Eritrea \\ *Corresponding author: Dawit Yikealo Gebretinsae: dawityikealo@gmail.com
}

Citation: Yikealo D., Karvinen I. (2018) Teaching Practice Program in the College of Education - its Strengths and Challenges. Open Science Journal 3(1)

Received: $7^{\text {th }}$ May 2018

Accepted: $8^{\text {th }}$ June 2018

Published: $2^{\text {nd }}$ August 2018

Copyright:@ 2018 This is an open access article under the terms of the Creative Commons Attribution License, which permits unrestricted use, distribution, and reproduction in any medium, provided the original author and source are credited.

Funding: The author(s) received no specific funding for this work

Competing Interests: The author have declared that no competing interests exists.

\section{Abstract:}

This research was conducted to evaluate the teaching practice program practiced every second semester in the College of Education (CoE) found in Eritrea Institute of Technology, Mainefhi. It explored the challenges and strengths of the program. To conduct this qualitative study, a questionnaire and a focused group discussion was used. A total of 104 participants (cooperating teachers, student teachers and supervisors)were selected for the study. The findings reveal that the teaching program in the $\mathrm{CoE}$ is practiced in a short time span with difficulties in materializing the proposed budget by the CoE and other challenges that vitiate its quality. However, the involvement of the cooperating teachers (CTs) and supervisors is satisfying. Majority of the student teachers (STs) felt that the practice plays a great role in preparing them for the teaching profession. Therefore, generally solving the budget implementation issue and the minor drawbacks of the program will definitely make it contribute a lot in producing qualified teachers. Finally, these findings are expected to mitigate the limitations of the program and raise the outcome of the practice. Besides, other initial teacher education institutes may benefit from the study findings.

Keywords: Teacher, Teaching Practice, Cooperating Teachers (CTs), Student Teachers (STs) 


\section{Introduction}

Education is increasingly becoming important for the success of both individuals and nations. This is evident in the great innovation of educational resources. Teachers and their abilities have a leading status which secures students' learning condition. Therefore, the demands on teachers are increasing (Darlin-Hammond, 2006). Darlin-Hammond (2006) also added that:

Teachers need not only to be able to keep order and provide useful information to students but also to be increasingly effective in enabling a diverse group of students to learn ever more complex material. In previous decades, teachers were expected to prepare only a small minority for ambitious intellectual work, whereas they are now expected to prepare virtually all students for higher order thinking and performance skills once reserved to only a few. (p.300)

Azeem (2011) explained the teaching profession as an exciting and rewarding activity but like other professions it is demanding. It requires practitioners to clearly understand the profession and conveythe most desirable learning to their pupil. They need to be highly proficient in the skills necessary to carry out these tasks. Teaching is not the simple matter of profession; rather it is complicated communication field. Teachers reflect their communication skills through various teaching methods, techniques and devices. Teaching methods are leadingmeans of communication whereby teachers bring about the desired learning. A professionally trained teacher can use different methods of teaching successfully. It is really a very difficult task and only a professionally qualified teacher can fulfil it.

To describe the power of a teacher and the teaching profession Bezzina, Lorist, and Velzen (n.d) also noted that teaching is a very multifaceted profession and continuous in nature. It grows within the teaching profession and hence through the daily academic experiences. Becoming a teacher goes beyond mastering a subject matter and acquiring adequate skills. It is transformational in nature. It is, first and foremost, about developing one's own personal and professional identity. Such an identity can be obtained and enhancedthrough involving in the various school practices and in the daily life of teachers.

Furthermore, Block (2011) explained that to be a teacher is to be brave. It is teachers who engage daily in making small and large decisions. They are those who remain attentive despite the countless distractors and tedious working environments around them. They are very much assertive to their wills and exert limitless efforts to meet the demands of their students and make their job productive. Block (2011) further explained that teachers are responsible for learning process. It is teachers produceall doctors and priests. Teachers are brave not because they stand "on the front lines" nor function "in the trenches," but because they have accepted the discipline explicit for the moral equivalent of war. Teachers serve as moral exemplars in all their daily academic and social activities.

The importance of powerful teaching is increasingly becoming important in contemporary society. Standards for learning are now higher than they have ever been before, as citizens and workers need greater knowledge and skill to survive and succeed (Darling-Hammond, 2006). Decade's reformation in education system realizes that strengthening the quality of teachers in a country contributes in 
building a civilized nation. Thus, investment in producing qualified teachers is indirectly building and securing the nation with sustainable production enlightened man power (Feiman-Nemser, 2006). Teacher education institutes create many configuring ways in enhancing the knowledge and skill of STs (Darlin-Hammond, 2006).

To conform the professional requirement of a teacher, teacher education institutes must design programs that enhance the understanding of the prospective teachers in pedagogic as well as social and cultural contexts. These might include teaching and classroom management skills. Thus, the participation of STs in teaching practice works as preparatory and transitional period to become a teacher (Darling-Hammond, 2006). "When internships include opportunities for students to reflect on their own work, powerful insights and integration indeed are possible" (Baum, 1997, p.22). Feiman-Nemser (2001) also added that the core tasks of the internship period focus on thinking about what teachers need to know, care about, and be able to do in order to promote substantial learning for all students. They also explained that the images and beliefs that STs bring to the practice influence what they are able to learn from the practice.

The process of learning to teach has been known as highly complex, personal, life-long and bothering some with challenges. It is a profession, like law with its own professional guideline and procedure to serve the public. It incorporates responsibilities in handling students' problems and demands. It demands teachers to familiarize with the context they are. Teaching also builds and draws upon multiple bases of knowledge simultaneously (Baxan and Broad, 2017).

In the process of becoming a teacher, providing the opportunity for teaching practice has a vital role. Teaching practice is a practicum in which prospective teachers involve mostly in their final year of study as part of the pedagogic requirement. It is an important and integral component of becoming a teacher. It grants STs experience in the actual teaching and learning environment. Kiggundu and Nayimuli (2009) defined teaching practice as a form of work-integrated learning period of time where students engage in applying theories in practice in a relevant industry to receive specific in-service training. They also added that during teaching practice, STs have a time for observing and practicing the art of teaching before they start an independent teaching. The practice help STs then to know the value of teaching practice and they perceive it a supportive duty that prepares them for the teaching profession. The practice influences the STs' perception of and attitude towards the teaching profession. Though STs encountered positive experiences during teaching practice, STs experience challenges which affect their perception of the teaching profession. Thus, there is always an initiative on how to improve teaching practice in order it to have a positive influence on the STs' perception of, and attitude towards the teaching profession. Similarly, Azeem (2011) explained that "teaching practice embraces all the learning experiences of STs in schools. The term practice teaching has three major connotations: the practicing of teaching skills and acquisition of the role of a teacher; the whole range of experiences that students go through in schools and the practical aspects of the course as distinct from theoretical studies"'(p.309).

Teaching practice aims at providing STs with practical experience in schools. It specifically targeted to enhance STs' abilities to further develop their 
knowledge and skill in the educational courses and apply them in teaching pupils in schools. During their practice student teachers will practice on how to draft their own lesson plans for all activities they plan and lead themselves accordingly. They learn appropriate ways of managing their classrooms, organizing whole class or group of pupils' activity, facilitating and monitoring pupils' learning, evaluate each lesson they deliver and strengthening their future plans in light of it and acquiring a good understanding of the role of a teacher (University Brunei Darussalam, 2008).

The University Brunei Darussalam (2008) in its handbook mentioned that the teaching practice courses represent the finale preparation for a ST to become a qualified teacher. It also added that teaching practice consists of an extensive period of school-based practice which includes observations, discussions, planning, teaching, assessing, evaluating and reflecting. STs practice teaching undera close supervision. The first days of the teaching practice at school are occupied for observing a range of teaching and learning situations, familiarising him/herself with school routines and activities, gathering information needed for teaching tasks, and planning and discussing lessons with CTs. Thereafter, STs will gradually build responsibility and certain techniques to handle classes, taking on the planning and assessment responsibilities of teaching for the whole time of their practice. Finally, their respective institute will expect them to reflect their teaching practice experience.

\section{Background of the study}

The Eritrean Initial Teacher Education Colleges (EITEC) produces teachers to work in elementary, middle and secondary schools of the country. The colleges give various pedagogic and related courses known to be helpful in preparing STs for the teaching profession. As part of the activities of the colleges, STs are provided with the opportunities to practice the teaching profession in Asmara elementary, middle and secondary schools. As the teaching practice is one of the practicum courses given to students in these colleges, the colleges design their own directing or administering procedures in benefiting STs from the practice. In Eritrea, the teacher education program is given only in two colleges. One is Asmara Community College of Education (ACCE) found in Asmara (Paradizo) and the second is College of Education ( $\mathrm{CoE}$ ), located in Mainefhi.

In the College of Education found in Eritrea Institute of Technology (EIT), Mainefhi, prospective graduate students under the departments of English language teaching, science education, social science education, and physical and health education usually participate in the teaching practice program. The program is meant for both diploma and degree program students. Thus, STs are assigned to practice teaching in junior and middle schools. It is about one month program which is directly a continuation to the Micro Teaching (MT) program practiced in the college. The practice starts immediately at the beginning of the second semester where students are made to stay in Asmara for the practice purpose without attending their regular semester classes. During their practice time, supervisors from the college are assigned to assist and supervise STs. The supervisors check the attendance, lesson plan, lesson notes, observation sheets 
and the progress of the contextual analysis script. At last, marks are allotted to each task accomplished by STs. Moreover, the supervisors are responsible to evaluate the teaching skill of STs. In doing so, the supervisors get assisted by the involvement of CTs in mentoring and evaluating the STs(College of Education, 2017).

The program is in action in the CoE far from the commencement of the CoE in University of Asmara (UoA). The program was going through many modifications in its procedures for having effective outcomes. The university lastly in 2006 used a revised manual for directing the practicum program which is applicable for both degree and diploma programs (Adgoy, et al., 2006).Though there is similar procedure being practiced currently in the CoE, it doesn't mean that no important modifications has made. As a new and additional requirement of the practice, STs are made to involve in MT program in the college, since the academic year 2013/14. This program prepares STs to practice teaching in a simulated environment which is expected to contribute a lot in practicing teaching in the schools. Besides, after completion of the practice STs have also a specified time to reflect and share their experience of teaching in their respective schools (College of Education, 2017).

\section{Aim of the research}

This research is aimed at exploring the strengths and challenges of the teaching practice program in the College of Education (CoE).

\section{The Rationale of the research}

The researchers are intended to evaluate the teaching practice program in the $\mathrm{CoE}$ as teaching practice is the core task of the teacher education institutes (teacher producing institute).therefore, the researchers have the believe that the practice program in the $\mathrm{CoE}$ should be contribute more in producing qualified teachers. Besides, through exploring the practice the researchers have the intent to see how such a practice is done in other teacher education institutes. Finally, the researchers believe that the study will have a great contribution in making the teaching practice program in the college effective through recommending profitable mechanisms in diminishing the identifiable problems.

\section{Research Objectives}

This research conducted to meet the following specific objectives,

- To explore the significant strengths and weaknesses of the teaching practice program in the College of Education (CoE).

- To examine the readiness of STs to the practice as well as their maturity for the teaching profession.

- To know how the program is planned. 
- To examine the involvement of cooperating teachers (CTs) in mentoring STs.

\section{Research Questions}

In this research, the researchers identified the following questions,

\section{Main Research Question:}

$>\quad$ What are the significant strengths and major challenges of the teaching practice program in the College of Education?

\section{Sub-Research Questions:}

$>$ How is the time and budget allocated for the practice?

$>$ How effective the program is in its planning?

$>$ How are the beliefs and attitudes of the STs to the teaching profession?

$>$ How are the supervisors and CTs in mentoring the STs?

$>$ What strategies do supervisors and CTs use to support STs during their practice?

\section{The objectives of teaching practice}

According to Akbar(2002) as cited in Gujjar (2016) the specific objectives of teaching practice is enumerated as follows:

1. To provide the prospective teachers with the opportunity of establishing an appropriate personal relationship with administrators, teachers, parents and students. This helps them to STs also get an opportunity to liaise with school environment, its functioning and with community and its resources.

2. To provide for the exchange of ideas and methods between practicing school and teacher training institution, by teacher training institutions' staff and students, perceiving new ideas material and equipment in use in practicing schools and introducing new ideas, material and equipments into the school.

3. To provide an opportunity for evaluating the student potential as a teacher and suitability for the teaching profession. STs get the opportunity to have teaching evaluated and to gain from the benefits of constructive criticism. This helps them then to discover their own strengths and weaknesses.

4. To provide with an opportunity to put theories into practice and to develop a deeper understanding of educational principles and their implication for learning. This provides the future teacher with practical experience in school to overcome the problems of discipline and enable him/her to develop method of control.

5. To enable the STs effectively use fundamental procedures, techniques and methods of teaching like to plan and prepare lessons.STs develop important teaching skills like fluent speaking, meaningful reading, using blackboard and other teaching material. 
6. To develop desirable professional interests, attitudes and ideas relative to teaching profession. STs are able to acquire desirable characteristics/traits of a teacher and to display appropriate behaviour.

\section{The importance of teaching practice}

As noted by Kiggundu and Nayimuli (2009) "Teaching practice is an important component of becoming a teacher. It grants STs experience in the actual teaching and learning environment"(p.345). Similarly a study byMtika (2012, p. 552) revealed that"teaching practicum as it is integral to trainee teachers' professional development, and shapes their beliefs and thinking about teaching. Trainee teachers consistently describe teaching practicum as the most valuable element of teacher education".

Marais and Meier (2004) cited in Kiggundu and Nayimuli (2009) also argued that teaching practice contributes much in enriching the STs' experience. They get the opportunity to face the challenges of the teaching which enhances their desire to maximize their benefit from the practice. Besides, by involving STs in teaching practicum teacher training institutions could fully understandthe student teachers' experiences and recognize the challenges faced by student teachers. They could recognize both the positive and negative experiences of student teachers during teaching practice. This awareness could help teacher education institutes to be effective in implementing a positive teaching practice experience through reconsidering and reviewing the student teachers' experiences. As a result, the institutions will suggest and then enable student teachers to achieve the desired outcomes from the teaching practice.

Perry (2004, p.2) as cited in Kiggundu\&Nayimuli (2009) also points out that;

STs should experience the excitement of being a part of a real classroom setting, of getting to know learners, of planning and organising the classroom tasks. On the other hand, STs could have doubts about their ability to cope with unfamiliar situations, controlling and managing learners or establishing a working relationship with the mentor or supervisor. It is such mixed feelings that can contribute to the making or breaking of a student teacher.(p.347-348)

Baum (1997) pointed out that in teaching practice STs integrate academics, classroom teaching, and theory to practice. The practicum provides the opportunity for student teachers to reflect their own work, develop powerful insight and integration.

According to Brown and Brown (1990, p.2-3) cited in Azeem (2011, p.311) the importance of teaching practice is noted as;

- An opportunity to gain confidence.

- Chance to put theories into practice.

- An opportunity to learn the skills and attitudes of a competent and affective teacher.

- The chance to learn about children in real life.

- An opportunity to improve the knowledge of subject matter.

- The chance to gain from the benefits of constructive criticism.

- An opportunity for self-evaluation and to discover strengths and weaknesses.

- An opportunity for the teaching institutions to evaluate itself. 
Similarly, Merryfield (1997, p.124) as cited in Azeem (2011, p.311) shows the following opportunities that teaching practice creates for STs:

- To apply knowledge and skills acquired in teacher education course work.

- To demonstrate attitude consistent with good teaching.

- To apply multiple principles of learning and multiple teaching strategies.

- Begin to identify with the role of a teacher.

- Develop entry-level competence in the full range of teaching function.

- Demonstrate professional and ethical behaviour.

Perry (1998, p.23) as cite in Azeem (2011, p.311) also narrates that teaching practice experiences contribute in some way to understanding of teaching. It helps to learn to use teaching experience it involves:

- Developing specialized knowledge

- Using the knowledge to access and make decisions

- Acquiring high standards of practice

- To develop knowledge and abilities in relation to each of these aspects.

\section{The plan for the practicum}

"Planning is a practice, a way of acting that can be called acting plan fully. Its essence is acting with knowledgeable hypotheses about the consequences of alternative courses of actions. The core of planning competence is reflective planning, the ability to use knowledge in action"' (Buam, 1997, p.21). Drafting an effective plan is a challenge in the teaching practicum program. As it is described by Baum (1997) the program should encourage and enable faculty members to participate in planning the program, alone or with the students. Their involvement will help them know what they should do in the practice. It truly guides them the STs actions and how they can mentor them.

Macharia and Wario (1994, p.8) as cited in Azeem (2011, p.311-312) shows that to orient STs with the plan of the teaching practice program meetings are held to give the students the necessary information about their teaching practice. The teaching practice coordinators together with the supervisors give out the necessary information of such as matters as procedure for observation days, on assessment, on appropriate dress, on learning aids, etc. STs can ask questions about any aspect of teaching practice that concerns them. The student teachers should be told about their transport and about the times they are supposed to board the buses to and from the school. All the students going on teaching practice should attend teaching practice programs.

According to Bahrain Teachers College (2016), teaching practice includes the following three core areas in its plan:

1. Observation:

Bahrain Teachers College (BTC) students are required to observe their CTs and other teachers in and outside of their classrooms order to learn from their experiences and practices. To ensure the quality of these observations, students are required to complete a specific number of observations per day under the supervision of their CTs.

2. Teaching:

BTC students are expected to prepare lesson plans and to teach partial or 
full periods depending on their year and under the supervision of their CT and TP supervisor.

3. Reflection:

BTC students are required to reflect on their and other practitioners' teaching strategies and practices by composing thoughtful reflections on their daily lesson plans, reflecting on a video recording of their own teaching, and writing a teaching philosophy statement depending on their year. Reflections are discussed during teaching practice seminars.

Similarly, the University of Brunei Darussalam (UBD) in its 2008 handbook mentioned that the student teachers should be acquainted with the following action plans:

- The institute will assign one/two $\operatorname{Supervisor(s)}$ from the institute as well as one / two CT(s) from the school, who will provide STs with information and advice on preparation and teaching. The STs are also informed to work closely with them.

- The supervisor will visit from time to time to assess and counselSTs on matters relating to teaching practice. However, if STs need further counselling STs can make an appointment to see the supervisor from the university after school hours or keep in contact by email.

- Consulting CT(s) for advice and guidance at all times when in school.

- The STs'teaching practice supervision will be done by the CT(s).

\section{Time allocation}

In Erasmus University Rotterdam, each year STs, CTs and supervisors engage in an intensive 13-week teaching practice. During the practice, mentors and STs conduct regular meetings and discussions (Cook-Sather and Youens, 2007). Kiggundu and Nayimuli (2009) noted that STs in Vaal University of Technology (VUT) are required to do at least 12 weeks of teaching practice. It is scheduled for the second semester (fourth quarter) from August to October. During the time of this practice, STs continued attending lectures at VUT.

A study conducted by Mtika (2011) in one of the Malawi's main public teacher education institutions revealed that teaching practicum for the degree program is conducted in two-phases and each phase lasts for 6 weeks. The first phase takes place at the end of second year while the second phase takes place at the end of third year. This offers STs an opportunity to relate and interrogate their coursework knowledge, theories and assumptions about teaching and learning.

The Bahrain Teachers College (BTC) in its part sends degree program STs to practice teaching in the entire of their college years (first, second, third, \& fourth). The time allocated for first, second and third year students is 20 days. However, the fourth year students are required to practice teaching in the entire of their fourth year. The credit hour allocated to each level from first to third year is two. Whereas, for forth year students it is nine as they practice it throughout the semester (Bahrain Teachers College, 2016). 


\section{Budget allocation}

According to Nigerian Education System, in the early 70s to 80s STs are given salary based on their program of their education; degree and diploma program STs paid differently. This salary mitigates problems identified during the teaching practicum. Therefore, the STs will have no excuse not to use that money to purchase the basic instructional materials for effective teaching. However, the economic down turn of the late 80s forced government to withdraw this financial assistance. The result is that students now go out for practice teaching ill-equipped financially. The outcome of the teaching program then dropped down automatically (Nakpodia, 2011).

Findings from a study conducted by Lorist and Utrecht (n.d) revealed that the Dutch government allocate funds and a number of schemes were developed in partnership of the schools and teacher training institutes. The schools and teacher training institutes were free in designing how the co-operation process should work between the partners. Partnerships became opportunities for schools and institutes.

\section{The involvement of Cooperating Teachers}

CTs work responsibly by spending quality time in coaching the STs. During the practice, CTs involve by creating the opportunity for STs to observe their classrooms, asking questions and receiving assistance and gradually assuming increasing personal responsibilities as his/her knowledge and skills develop (Lorist and Utrecht, (n.d)). Furthermore, Lorist and Utrecht (n.d) explained that "the CTs initially models the task for the ST, and then provides coaching (i.e. instructions, feedback) as the ST attempts the task, fading the amount of coaching and turning over more and more responsibility for independent task completion to the ST as his/her skills develop"' (p. 750).

Roth and Tobin, (2001) as cited in Mtika (2011) revealed that CTs who work as direct mentors of STs are likely to create better relationships with college supervisors and STs based on mutual respect and understanding for each other's expertise, needs and perspectives. This might possibly mitigate many difficulties that challenge STs during their practice. Though this type of mentoring facilitate primarily aimed at facilitate high quality professional learning for STs, it also benefits the CTs by creating opportunities for life-long learning through cogenerative dialoguing with STs and college supervisors.

\section{The college supervisors' responsibility}

The supervision process during teaching practice aims to promote good practice among students in classrooms and to affirm and acknowledge best practices. It seeks to improve the quality of teaching offered by students and it promotes self-reflection and continuous improvement in the development of pedagogic skills among students. It also allows students to get support from experienced professionals and practitioners (Foncha, Abongdiaand Adu, 2015). "During teaching practicum, college supervisors are expected to visit each trainee teacher on a weekly basis but this is rarely the case. The supervisors observe each 
trainee teacher and hold post-observation conferences with each one of them as part of the assessment of teaching practicum" (Mtika, 2011, p.555-556).

A practice in Vaal University of Technology Postgraduate Certificate in Education shows that during the school visits, supervisors are expected to give the STs written and oral feedbacks. Improvements were commended, shortcomings highlighted and suggestions made on how to, for example, overcome anxiety, use non-teaching practice verbal language to enhance their teaching and learning activities, and how to apply a variety of strategies to improve their teaching (Kiggundu and Nayimuli, 2009).

\section{Research Methodology}

This research is approached with the help of a descriptive research design. The study is a qualitative study which is suitable for extracting relevant information about the practicum program practiced every second semester in the college of education. Qualitative method was employed because it could answer all the research questions and be good in attaining the objectives of the study, too. As qualitative studies by nature are an in-depth portraits of a specific issues (Wenglinsky, 2001), the researchers believes that the information from the participants will be helpful to confidently evaluate the program.

\section{Sample Size}

The researchers have selected participants for the study from the CoEfound in Eritrea Institute of Technology (EIT) and the sample six schools in Asmara. The participants were college instructors (supervisors), CTs from six middle and secondary schools in Asmara (Barka secondary school, Isak $\mathbf{T} /$ medhin secondary school, Keih-Bahri secondary school, Dalulmiddle school, Awet elementary and middle school and Adulismiddle and secondary school) and STs from the college (from both degree and diploma program).

Table 1 shows the number of participants selected for the study purpose from the CoE and the six selected sample schools in the capital.

\begin{tabular}{|l|c|c|c|c|}
\hline College/School & $\begin{array}{c}\text { Number of } \\
\text { Supervisors }\end{array}$ & Number of CTs & Number of STs & Total \\
\hline College of Education & 14 & 30 & 60 & 34 \\
\hline Six Sample Schools & 14 & 30 & 60 & 104 \\
\hline Total & & & & 30 \\
\hline
\end{tabular}




\section{Instrument}

The researchers have collected the required data with the help of focused group discussion and self-administered questionnaires. For this purpose, the researchers used self-developed open ended questions for collecting data from the sample supervisors of the CoE. Besides, the researchers used two types of selfdeveloped questionnaires for gathering information from the sample CTs of six schools in the capital and STs from the college. The questionnaires were prepared to be self-administered easily.

\section{Data Analysis}

The data obtained from the participants with the help of the questionnaires and focus group discussion was analysed qualitatively. To process the data analyses, the researchers utilized thematic data analysis where the data summarized and organized qualitatively. In this, the researchers use tables to display the counts for some of the items. Besides, in most of the analysis process the responses were merge in certain major themes that simplifies the data presentation. The data obtained from the different group of participants is triangulated and certain gaps in responses were identified.

\section{Procedures and Ethical Considerations}

To conduct the study, the researcher utilized a self-developed questionnaire for STs and CTs, and discussion questions for the supervisors from the college. The self-developed questionnaires were distributed to the sample selected and focus group discussions were also conducted with the sample supervisors. The researchers specified the distribution and discussion time and place in advance. For the focus group discussion, the researchers get the consensus of each participant and arrange a convenient time for all the participants. The focus group discussion was conducted in two sessions with seven participants in each. These discussion sessions took about two hours each. The time for the discussions extended from about 12:30 p.m. to 2:30 p.m. Therefore, during the discussion the sufficient time and the small number of participants in each session encourage participants to give their own opinion in every issue of discussion. To facilitate the focus group discussion sessions, the researchers nominate one instructor to record the opinions of participants. The researchers have led and facilitated the discussion by sticking to the focal questions prepared in advance.

In distributing the questionnaires, the researchers applied an informed consent. The researchers briefed participant CTs and STs about the purpose of the study so as to avoid some hesitations in responding and to get genuine information about the practicum. During the distribution of questionnaires, the researcherswerepresent to guide and help participants in case there is some ambiguity with the items in the questionnaires. For this purpose, the researchers contacted STs in their classrooms. This is done by negotiating with instructors of the STs to facilitate and get time to distribute the questionnaires.

To validate the questions prepared for all the participants, the research tools were reviewed by experts under the Research and Development Unit (R\&D unit) 
in the $\mathrm{CoE}$, experts in the college and education specialist from the Finish Church Aid (FCA) project. Through these rigorous experts' comments and suggestions, the researchers developed highly relevant items to the objectives of the study. Furthermore, these experts keenly edited the final draft of the research paper. They commented in all aspects of the preparation including the language usage.

The questions for all the subjects were made to reveal the clear picture of the teaching practicum in the college. The main concern of the questions was to explore the situation of the program in its planning, time allocation, budgeting and supervision procedures of the practicum. Besides, the research tools were also embedded with items that investigate the involvement and understanding of the CTs as well as the STs.

\section{Results}

\section{The plan for the practicum}

The participants of the two sessions' focus group discussion confidently explained as the teaching practice program is good with scheduling the time, preparing supervisors and STs for the practice. They also added that it is a good procedure to start the practice with the Micro Teaching (MT) program. Micro Teaching program was addressed as one of the most valuable actions included in the plan. However, the MT program with its difficulties. The time is not convenient as it is lunch time and some STs also engage in lab trainings. Though the STs one month stay is attempted to be smooth with the effort of the coordinating committee, there are always complains with regard to time and accommodations.

The most bouncing issue of the participant supervisors was in the 'implementation of the proposed budget' for the program. This issue is known to be every year's concern and still going unsettled. The participants underscored as this budget case definitely lessens the outcome of the program.

Lack of communication with the schools in advance to facilitate the program was also a concern of some supervisors. Some participants expose their idea in selecting coordinating committee members. They claimed that the committee should be composed of experienced and dedicated instructors from the college. A few members of the discussion reminded that the plan should include a mechanism to update the old manual, which were used in the University of Asmara (UoA).

Results from the questionnaires distributed among the CTs revealed that, around one fifth of the participant CTs evaluated the plan as it was excellent. They added that the plan was made practically applicable in all round. The same number of participants said that the plan was very good. More than half of the participants believed that the plan for the program was good. Whereas, a very few of them said that the plan for the program was having problems like shortage of time, interruption to school actions or plans, etc. Therefore, they labelled the plan as poor. 


\section{Time allocation for the practicum}

With regard to the time allocated for the teaching practice program, most of the focus group discussion participants reported that the time is not enough for the STs to practice and know much about their pedagogic skill as well as the requirements of the teaching profession. However, they strike a chord that it is difficult to extend the time for the practice. This is because the location of the college doesn't guarantee conducting the practice in an extended period of time. Besides, if the time given for the practice increased, STs will face more trouble to cope in their return to their home college. They are overloaded with makeup classes to catch up the time. As the college of Education work hand in hand with the College of Science, the STs who take courses with the college of Science would be endangered.

Half of the number of participant CTs evaluated the time allocated for the practice as it was enough. They assured that the time was sufficient enough for the trainees to benefit from the program. More than one third of the CTs also opposed the length of time allocated for the practice and evaluated it as it was short. A very few of them also evaluated the time as it was very short. Similarly, a very few number of the participants has evaluated the time allocated as it was more than enough.

Contrarily to the supervisors' report, only three of the participantSTs said that the time allocated for the practice was very short. Nine of them evaluated the time as it was short. Eight of the participants also said the time was fair. Around half of them evaluated as it was sufficient (enough). Five of them informed that the time was more than enough. The rest few of them were having different and irrelevant responses about the question asked.

\section{Budget allocation for the practicum}

Definitely, all the participants of the discussion sessions revealed that there is a big problem in materializing the requested budget for the program by the CoE. They recommended that the budget for the program should be facilitated smoothly and paid in advance. It should also be very clear for the admin office that the program is every second semester's duty of the college. Coordinators should not knock the door of the admins for budget sake. The participants informed that instructors from the college are forced to fulfil the financial expense for the betterment of the STs. They insisted as they are morally and professionally obliged to fulfil their duties. It is discussed that the effect of the budgeting problem is evident in the tremendous decrease in interest of the supervisors and frequency of supervisors' visits to the schools. At last the effectiveness of the program is severely harmed. 


\section{The attitudes and beliefs of the STs}

The discussions addressed as the attitudes and beliefs of STs towards teaching profession are showing improvement nowadays. However, it was not difficult for participants to read some implanted negative understanding of STs. Some of the evident feelings that the STs display during their practice time were;

- Isolation of the STs from the school teachers as a result of abhorrence of the profession. They don't like to stay and interact in the staffrooms with the school teachers.

- Lack of eagerness to know and do the task successfully with extreme carelessness.

- STs fail in preparing lesson plans, more absenteeism and stay in the schools for a limited time.

- Reluctance of STs to handle more loads.

Majority of the CTs also shared as they found the STs have a positive attitude towards the teaching profession. However, around five of them shared as the attitude and beliefs of STs towards the profession were moderate. They added that the STs have poor readiness and attitude towards the profession. They mentioned the various negative opinions about the attitudes and beliefs of STs like, a few of the STs are less interested, some take it as part time job and some get bored.

Besides, the result of the responses on the attitude of the participant STs towards teaching profession is represented in table 2 .

Table 2. The attitude of participants to teaching profession.

\begin{tabular}{|l|l|}
\hline $\begin{array}{l}\text { Attitude of participants towards the } \\
\text { teaching profession }\end{array}$ & No. of student teachers \\
\hline Positive attitude & 46 \\
\hline Negative attitude & 7 \\
\hline Other & 7 \\
\hline Total & $\mathbf{6 0}$ \\
\hline
\end{tabular}

As shown in table 2, majority of the participant STs have informed as they have a positive attitude towards the teaching profession. They shared as they have fond of the profession. Whereas, a few of them pointed out as they hate the teaching profession. The rest few of them replied as they have no idea; left it blank and others jotted irrelevant ideas.

\section{The involvement of supervisors}

The participants of the focused group discussion explained that supervisors are obliged to conduct classes in the college and at the same time expect to manage the supervision responsibility. Though it is difficult and having limitations, they contribute a lot to maximize their outcomes. As explained above, supervisors are obliged to engage in the program with no payment given in advance. The supervision responsibility with its limitations is exercised with the help of adherence to strong professional ethics of supervisors. Abided by professional demands, supervisors implement various procedures in mentoring 
STs and especially in modifying their wrong attitudes and beliefs. Some of the mechanisms forwarded by participants were:

- Designing a weekly reflection day that will help in identifying challenges and overcoming it.

- Having informal contacts with STs so as to break the gap and read their minds as well as giving guidance in a group level.

- Implementing various empowerment procedures like discussing about what is good in the teaching profession.

The participant STs in their part explained as there were differences in the involvement of supervisors from the college. Majority of them were very much dedicated and guide the STs responsibly. A few of them were simply coming to evaluate the STs by observing them during their classroom activity. However, some STs were also surprisingly said that many of the supervisors were reluctant in assisting the STs and less experienced in the teaching profession. Some STs informed even as they don't know their supervisors. Besides, some STs have motioned as many supervisors who don't live in the Asmara were bothering to fulfil the supervision responsibility and fail to visit the school as it is supposed to be.

Though there were differences among the degree of involvement of supervisors in mentoring their STs, the supervisors were reflecting various supportive actions falling in the following major areas. These areas are teaching methodology, supervision, time management, classroom management, socio-emotional support and others curricular and extracurricular activities.

\section{The involvement of Cooperating Teachers}

As most of the participants of the focused group discussions agreed, the involvement of CTs differ depending on the nature of the school they work. Some schools like the community schools in Asmara are strict in controlling the teachers and remind the CTs to pursue the activities of the practitioners. In these schools, the CTs work responsibly in mentoring the STs. whereas, some governmental schools are reluctant as thereby the CTs consider the STs as their substitutes. CTs in these schools fail to be responsible enough in mentoring and assisting student teachers to do well during their practice time. Some members of the discussion argued that the problem with CTs can arise from lack of orientation given by supervisors and regular contact of CTs and supervisors.

The participants CTs themselves informed as they were using various supportive actions for the betterment of the STs. All the participants reported that they were responsibly working in mentoring the STs during the practice time in their respective school. Similar to the supervisors reports, the main and most commonly stressed areas were teaching methodology, supervision, time management, classroom management, classroom assessment, socio-emotional support, sharing experience and others curricular and extracurricular activities.

The importance of the teaching practice for STs in the CoE 
All the focused group discussion participants believed that teaching practice plays a great role in providing practical learning experience and thereby producing qualified teachers. Though they have reservations with time of exposure (one-month), they confidently said that the practice work a lot and have a positive impact on the actual teaching life of the STs. Some of the advantages of the practice raised by the discussion members were:

- Attitude and knowledge of the teaching profession: STs get to know how the teaching and learning process going on. They will know the specific requirements of the teaching profession. Besides, they get the opportunity to know how responsible and accountable they should be as teachers for many duties and be prepared for their later career life. They came to know that they should act as humane as possible in their job.

- Content knowledge: STs know their status in the subject mastery and apply the theoretical knowledge they have to actual classroom practices.

- Develop the awareness of diverse student behaviours and problems.

- Read one's own skill in developing relationships, communication, and lesson delivery.

Similarly, the participant CTs and STs informed that the practice played a great role in the teaching profession of the STs. Furthermore, the participants reported as the STs were definitely benefited a lot in various areas of the practices of teaching profession as well as in their social and emotional wellbeing.

\section{Challenges encountered by STs during the teaching practice}

The researchers classified the challenges experienced by the STs during the teaching practice into two broad categories.

\begin{tabular}{|c|c|}
\hline Accessibility to necessary materials & $\begin{array}{l}\text { Challenges related to necessary services, } \\
\text { mentoring and classroom management }\end{array}$ \\
\hline$\bigvee$ & $\bigvee$ \\
\hline $\begin{array}{l}\text { - Teaching aids like charts, maps, globe, } \\
\text { textbooks, chalks, dusters, tape recorders, } \\
\text { audio-visuals tools like projectors and the like } \\
\text { relevant to their daily lessons, lab chemicals. } \\
\text { - Lack of access to printers and photocopiers. } \\
\text { Having old blackboards }\end{array}$ & $\begin{array}{l}\text { - Disciplinary problems of the students in the } \\
\text { - Dchools } \\
\text { cafeteria services } \\
\text { - Transportation } \\
\text { - Lack of proper mentorship, problems in } \\
\text { fulfilling the teaching professionalism, financial } \\
\text { problems, }\end{array}$ \\
\hline
\end{tabular}




\section{Discussion}

The successful accomplishment of any project begins with effective planning. A program is required to spend time and effort in drafting a good plan. It requires expertise to have skills, care and experience to design an appropriate plan.

The CoE conducts the teaching practice program every second semester of academic years with drafting a feasible plan at least by the coordinating committee. As explained by the supervisors from the college, a workable plan is usually stated that leads the practice. It includes time schedule of all the activities of the program, accommodations for STs, assignment of STs as well as supervisors to their respective schools, and the responsibilities of STs, CTs and supervisors. Time schedule is so concrete which precisely guide the activities of STs and supervisors during the practice. All these aspects are given to STs and supervisors via the program manual. Further more, the MT program is scheduled and practiced by assigning supervisors and STs, though is conducted in an inconvenient time. This program is facilitated by providing a classroom for each group of STs to practice teaching in a simulated classroom environment.

A Similar experience in Bahrain Teachers College (BTC), an agreement is signed by CTs, STs and school teaching practice coordinators and submitted to teaching practice supervisors during the first week of every teaching practice period (Bahrain Teachers College, 2016). Similarly, the plan for the practicum in CoE includes reaching agreement with stakeholders in the Ministry of Education of the central zone in advance. The office is then shouldered the responsibility to notify each school to cooperate STs and supervisors from the college in their stay in the schools. This helps to assure the smooth going of the program and mitigate barriers during the practice.

In this research, majority of the participant CTs revealed as the plan for the practice was having no difficulties. However, the participant supervisors from the CoE explained as the program fail in implementing the proposed (planned) budget. In their point of view, despite the budget is clearly stated as determinant aspect of the plan, there is hindrances in facilitating it at the EIT admin office. In concord to the experiences of the CoE teaching practice program, a study by Ranjan (2013) revealed that all respondents pointed out that practicing teaching is planned quite well especially at preparation in the institution and then going out for the block teaching and then in the second semester off campus and internship programme. However, some of the respondents have said that executing the teaching practice before and after the examination is not appropriate. Lesson planning was very inconvenient, while at the same time they were required to do their own assignments for the fulfilment of their academic qualification. It was a challenge having to do both at the same time.

The teaching practice program in the CoE troubles in materializing the proposed budget though it budgeting plays a great role in strengthening the program. The budget issue is very much confusing and demotivating, especially for the supervisors from the CoE. The participant supervisors underscored that the budgeting is determinant for the overall outcomes of the teaching practicum. They strongly reminded that they experience limitless troubles to be paid for their commitment in the supervising duty of the teaching practice program. This happens though the supervisors are forced to cover the transportation and other 
expenses as they go to visit the schools in Asmara. This rooted from inability to materialize the budget proposed for the teaching practice program. However, usually the coordinating committee of the program propose clearly the required budget and submit it in black and white to the admin and finance office of EIT.

In contrary to this experience, a study in the Dutch government reported as enough budgets is allocated for the practice program where the teacher training institutes and schools can freely cooperate and secure the vigorous outcome of the practice (Lorist and Utrecht,(n.d)). Furthermore, the study shows that there is no incentive given to STs. Therefore, STsb other in affording certain expenses in their stay in Asmara, especially the transportation expenses. Likewise, findings from the Nigerian educational system supports that withholding incentives of STs dramatically lowered the effectiveness of their teaching practice (Nakpodia, 2011).

The time allocated for the practice is seen to be short as it is especially explained by the supervisors form the CoE. It is not comparable to the time given in other institutions overseas. However, extending the time is known to be infeasible as the CoE is found $26 \mathrm{~km}$ away from Asmara. A different experience from this, the teaching practice manual prepared by Adgoy, et al. (2006) explains that the program was a whole semester's internship. However, this is possible because the CoE under the UoA was in Asmara. Thus, STs as well as supervisors can normally engage in middle and secondary schools in Asmara while the regular classes are going on in the college.

Similarly, in Pakistan teacher education institutes time allocated for the teaching practicum is very short. It is practiced from 4 to 8 weeks at the end of their last semester. This short time doesn't guarantee the STs' acquisition of all required skills from their engagement in the practice. Their practice is limited to classroom activities; don't go further to participation in other activities of the schools. STs are only introduced to the easy styles of teaching and practices of teaching (Gujjar, 2016). In contrary to the current CoE practices, in Malawi teacher education institutes, the teaching practice program is given in two phases of six weeks each. It is given at the end of second and third year. This creates enough time for STs to relate and interrogate their course knowledge, theories and assumptions about teaching and learning (Mtika, 2011).

The study addresses that majority of the STs are satisfied by the involvement of their supervisors and CTs. They responsibly work in coaching, guiding and supervising the activities of STs during their practice. They were supported in various areas like teaching methodology, classroom management, classroom assessment, time management and other curricular and co-curricular activities. They benefited a lot through sharing the rich experiences of the school teachers about teaching life. However, they have reservations with negligence of some supervisors and CTs in certain schools, especially in the public schools of Asmara. In line to this, Azeem (2011) reported that some respondents indicated that the CTs were supportive and always willing to share their valuable advice and skills, others felt exploited and unsupported by the mentors. Furthermore, a study by Sentamu-Namubiru (2010) as cited in Mtika (2011) reminded that visits by supervisors from teacher education institutions tend to be infrequent and therefore have minimum impact on STs.Findings from a study conducted by Maphosa et al. (2007) as cited in Azeem (2011) also suggested that mentors should be constantly empowered through workshops, to work effectively in 
leading and guiding STs. STs were not always made to feel welcome and were not generally respected by other staff members. STs were often excluded from many school activities and were made to feel insignificant which greatly demoralised them.

This research shows that majority of the STs have a positive attitude towards the teaching profession. It also discloses that the STs in the college are showing noticeable improvement in their attitudes nowadays. However, a very few STs have a negative attitude towards the teaching profession that resulted from the unfair placement procedure used in the higher education. They asserted that they joined the CoE without their choice. To enhance the attitude of STs, a study by Boikhutso (2013) cited in Foncha, Abongdia and Adu (2015) reminded that the teaching practice curriculum should include mechanisms that enhance the professional and personal growth of STs. It should work hard in making STs motivated, enthusiastic and independent teachers.

This study identified certain constraints that bother STs like lack of provision of some teaching aids like charts, maps, tape recorders, and laboratory chemicals, accesses to photocopy and print machines and so on. Unsatisfying accommodations like water supply, electricity supply, and transportation expenses and shortages are among the bothering some. Similarly, Ranjan (2013) expressed that the results obtained from the respondents with regard to resources revealed that the schools did not have sufficient resources to facilitate the teaching and learning process. Some of the respondents remarked that school library was having shortage of supplementary reading materials. Respondents indicated that they did not have access to the photocopying machine when they wanted to make copies of worksheets and other reading materials for learners.

In concord to the result of the present research, learners' discipline is a challenge in most South African schools and it appears that there are no effective disciplinary measures taken against delinquency and transgressions. In schools such as this, STs find it difficult to manage and control the class. In certain instances, learners know that STs are only at the school for teaching practice and as such cannot exert any authority towards them (Foncha, Abongdia and Adu, 2015). In addition, findings from the study conducted by Ngidi and Sibaya (2003) as cited in Wagenaar (2005) supports that a high level of anxiety among STs is inflicted as a negative consequence of class control problems and classroom disruptions.

Finally, based on the opinions of all respondents, the researchers believe that the teaching practice program plays a great role in providing practical learning experience and thereby producing qualified teachers in the CoE. Though they have reservations with insufficiency of practice time (one-month) and budgeting problems, they confidently said that the practice contribute a lot in familiarizing STs to the teaching practices and its responsibilities. STs could definitely benefit in acquiring various skills in teaching as well as social skills, too. The practice will have a positive impact on the actual teaching life of the STs. 


\section{Conclusion}

The teaching practice program in the $\mathrm{CoE}$ has a great contribution in the teaching proficiency of the college students. It is planned and implemented in consideration to minimizing certain reachable obstacles. The program has certain known factors that reduce the quality of the program's outcome on the STs, CTs and supervisors side. Yet, the practice prepares STs for their actual teaching life. The STs benefit much from the mentoring processes practiced by the assigned CTs and supervisors. The CTS and supervisors involve in helping the STs through various supportive actions that enhances their teaching skills as well as their personality as professionals. The involvement of the mentors also plays a great role in minimizing certain misunderstandings and beliefs about the teaching profession. This time the STs in the college are showing remarkable improvement in their beliefs and attitudes towards the teaching profession. Majority of the STs are found to have a positive attitude towards the teaching profession.

The intolerable budget issue is addressed as it plays a key role in determining the outcome of the program. It believed to affect the overall activities of the practice and involvement of all stakeholders can be influenced by the budget implementation in the program. Besides, the time allocated for the practice is seen to be short especially by the college supervisors' point of view. Nevertheless, as discussed by the supervisors elongating the time could have many uncontrollable negative consequences.

The importance of the MT program is underscored and addressed to be strengthened. MT is believed as it prepares STs for their actual practice. It helps them develop confidence and minimize difficulties in their teaching styles. However, some of the supervisors reported as the time for the practice is not convenient for STs, because it clashes with their lunch time and lab schedules.

\section{Recommendations}

- The EIT administration office should work responsibly in materializing the proposed budget for the program and provision of sufficient accommodations for STs to conduct the teaching practice.

- The researchers suggest that the $\mathrm{CoE}$ should call for workshops that participates officials from the Ministry of Education, school directors, representative CTs and STs as well as supervisors from the college.

- TheCoE should give recognition letter (letter of appreciation) or incentives to $\mathrm{CTs}$ so as to cultivate their intent to heighten their involvement in supporting STs. This can possibly improve the involvement of the CTs in mentoring the STs.

- The college should implement empowering procedures to cultivate the attitudes and beliefs of the STs towards the teaching profession like conducting seminars by experienced teachers in the country (role models) and other experts in the profession from different countries.

- The researchers suggest that as an alternative the college could conduct the teaching practice after STs completed their Diploma or Degree program 
classes in the college. The CoE can discuss and set the implementation of this alternative with the Ministry of Education.

- All preparatory courses in the college should be given in their appropriate time. Therefore, STs will benefit more from the courses and directly apply it to their practical works.

- The program coordinators should assign junior staffs as supervisors paired with the senior supervisors in fulfilling their teaching practice duty. Thus, STs will benefit more.

\section{Acknowledgment:}

This study received technical and financial support from Finn Church Aid. Mr.Efrem Teweldemedhin (Head, Programming Office, EIT) worked commendably in editing the whole contents of this research manuscript.

\section{References:}

Adgoy, F., Dumbuya, A., Ghebru, S., Machin, J. \&Tesfamariam, R. (2006).Teaching Practice Manual for Degree and Diploma Student Teachers (Rev. Ed.).University of Asmara: Faculty of Education.

Azeem, M. (2011).Problems of prospective teachers during teaching practice.Academic Research International, 1(2), 308-316.

Bahrain Teachers College. (2016).Teaching Practice. Retrieved on July 20, 2017 from http://www.btc.uob.edu.bh/details.aspx?id=aff71af9-f862-e211-b5dd-0022191ecece\&gid=3

Baum, S.H. (1997).Teaching Practice.Journal of Planning Education and Research, 17, 21-27.

Baxan, V. and Broad, K. (2017).Graduate initial teacher education: A literature review. University of Toronto: Ontario Institute for Studies in Education (OISE).

Bezzina, C., Lorist, P., Velzen, C.V. (n.d). Partnerships between Schools and Teacher Education Institutes. Paper presented at $31^{\text {st }}$ ANNUAL ATEE conference. Association of Teacher Education in Europe, 1, 47-758.

College of Education. (2017). Teaching Practice: Degree and Diploma manual 2016/17. Mainefhi.

Cook-Sather, A. \&Youens, B. (2007). Repositioning students in initial teacher preparation: A comparative descriptive analysis of learning to teach for social justice in the United States and in England. Journal of Teacher Education, 58(1), 62-75. doi: 10.1177/0022487106296216.

Darling-Hammond, L. (2006). Constructing $21^{\text {st }}$-century teacher education. Journal of Teacher Education, 57(3), 300-314. doi: 10.1177/0022487105285962.

Feiman-Nemser, S. (2011). From preparation to practice: Designing a continuum to strengthen and sustain teaching. Teachers College Record, 103(6), 1013-1055.

Foncha, J.W. Abongdia, Jane-Francis. A. and Adu, E.O. (2015). Challenges Encountered by Student Teachers in Teaching English Language during Teaching Practice in East London, International Journal of Education and Science, 9(2), 127-134

Gujjar, A.A. (2016). Teaching practice: Concepts, Stages, Objectives, and Suggestions. Retrieved on July 20, 2017 from http://www.eslteachersboard.com/cgi-bin/articles/index.pl?read=3490.

Kinggundu, E. \&Nayimuli, S. (2009). Teaching Practice: A make or break phase for student teachers. South African Journal of Education, 29, 345-358.

Lorist, P. \& Utrecht, H. (n.d). Partnerships between Schools and Teacher Education Institutes. Presented in $31^{\text {st }}$ Annual Association of Teacher Education in Europe (ATEE) conference. Christopher Bezzina: University of Malta.

Mannathoko, M.C. (2013). Does Teaching Practice Effectively Prepare Student-Teachers to Teach Creative and Performing Arts? The Case of Botswana. International Journal of Higher Education, 2(2), 115-121.

Marais, P. \& Meier, C.( 2004). Hear our voices: student teacher's experience during practical teaching. Africa Education Review, 1, 220-233.

Mtika, P. (2011). Trainee teachers' experiences of teaching practicum: Issues, challenges, and possibilities. African Education Review, 8(3), 551-56.doi: 10.1080/18146627.2011.618715 
OECD (2009). Creating Effective Teaching and Learning Environments. Retrieved on July 25, 2017 from https://www.oecd.org/berlin/43541655.pdf.

Ranjan, R. (2013). A study of practice teaching programme: A transitional phase for student teachers. Voice of Research, 1(4), 24-28.

Universiti Brunei Darussalam (2008). Handbook for Teaching Practice. Sultan Hassanal Institute of Education.

Wagenaar, M. (2005). Student teachers' experiences of practice teaching (Masters' thesis). KwaDlangezwa: University of Zululand.

Wenglinsky, H. (2001). Teacher Classroom Practice and Students Performance: How schools can make a difference. Princeton, NJ: Educational Testing Service.

Nakpodia, E. D. (2011). Teacher and the student practice teaching programme in Nigerian educational system. International Journal of Educational Administration and Policy Studies, 2(3), 33-39. 